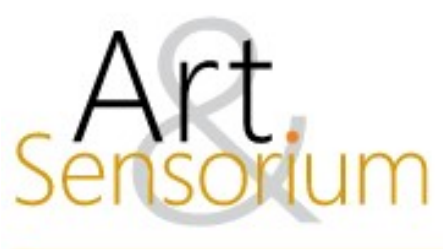

\title{
PERFORMANCE AUTOBIOGRÁFICA E O SENSORIAL NO DOCUMENTÁRIO CONTEMPORÂNEO: UMA PASSAGEM PARA MÁRIO (2014)
}

https://doi.org/10.33871/23580437.2021.8.1.001-008

\author{
Armando Castro ${ }^{1}$ \\ Ana Ângela Gomes ${ }^{2}$ \\ Beatriz Colucci ${ }^{3}$
}

Resumo: A partir da tríade performance autobiográfica, sensorialidade e linhas de fuga, uma reflexão sobre o filme Uma passagem para Mário (Eric Laurence, 2014). O artigo busca ampliar o debate sobre fronteira, esgarçamento e amplitude de uma linguagem cinematográfica comprometida com a arte contemporânea, a autobiografia, o devir, o afeto e a experiência/engajamento sensorial do outro.

Palavras-chave: documentário; arte contemporânea; performance autobiográfica.

\section{AUTOBIOGRAPHICAL PERFORMANCE AND SENSORY IN CONTEMPORARY DOCUMENTARY: UMA PASSAGEM PARA MÁRIO (2014)}

\begin{abstract}
From the triad of autobiographical performance, sensoriality and escape lines, the paper presents some reflections and analysis preliminary about the movie A passage for Mário (Eric Laurence, 2014). The article seeks to broaden the debate on the frontier, fray and breadth of a cinematographic language committed to contemporary art, autobiography, becoming, affection and the sensory experience / engagement of the other.
\end{abstract}

Keywords: documentary; contemporary art; autobiographical performance.

\footnotetext{
${ }^{1}$ Docente da Área de Música e Cultura do Centro de Cultura, Linguagens e Tecnologias Aplicadas da Universidade Federal do Recôncavo da Bahia (CECULT / UFRB) e do Programa de Pós-Graduação Interdisciplinar em Cinema da Universidade Federal de Sergipe (PPGCINE/UFS). https://orcid.org/0000-0002-9622-8004. http://lattes.cnpq.br/9116656578245485. E-mail: aaccastro@gmail.com

2 Docente do curso de Cinema e Audiovisual e do Programa de Pós-Graduação Interdisciplinar em Cinema da Universidade Federal de Sergipe (PPGCINE/UFS). https://orcid.org/0000-0001-7596-4777. http://lattes.cnpq.br/0832487473633507. E-mail: anaangelaufs@gmail.com

${ }^{3}$ Docente do curso de Cinema e Audiovisual e do Programa de Pós-Graduação Interdisciplinar em Cinema da Universidade Federal de Sergipe (PPGCINE/UFS). https://orcid.org/0000-0002-0559-3381. http://lattes.cnpq.br/9126793811301748. E-mail: biacolucci@gmail.com
}

R. Inter. Interdisc. Art\&Sensorium, Curitiba, v.8, n.1, p. 001 - 008 Jan.- Jun. 2021 


\section{RENDIMIENTO AUTOBIOGRÁFICO Y SENSORIAL EN DOCUMENTAL CONTEMPORÁNEO: UMA PASSAGEM PARA MÁRIO (2014)}

Resumen: De la tríada de actuación autobiográfica, sensorialidad y líneas de escape, una reflexión sobre la película Un pasaje para Mário (Eric Laurence, 2014). El artículo busca ampliar el debate sobre la frontera, el deshilachado y la amplitud de un lenguaje cinematográfico comprometido con el arte contemporáneo, la autobiografía, el devenir, el afecto y la experiencia sensorial / compromiso del otro.

Palavras clave: documental; arte Contemporaneo; Rendimiento autobiográfico.

\section{Introdução}

A vida-morte do amigo Mário Duques é o centro do primeiro longa documentário do diretor Eric Laurence. Em Uma passagem para Mário (2014), aborda aspectos relevantes da condição humana: a amizade, o episódio da morte enquanto passagem, os sonhos, a espiritualidade, as utopias etc. Neste contexto, as experimentações de um jovem diretor pulsam por registrar, respeitosamente, a condição do amigo doente, sua trajetória, os registros audiovisuais dos últimos dias de vida, tudo distante de uma narrativa de vitimização deste, mas como memória afetuosa e sensível.

Mário Duques era um psicólogo e mergulhador pernambucano portador de câncer no fígado, em estágio terminal. Sabendo disso, realiza uma série de registros do seu convívio familiar, social e profissional, que passam a compor o próprio filme, motivado pelo sonho da dupla de realizar uma viagem até o deserto do Atacama, no Chile, saindo de Recife e passando por algumas cidades da Bolívia. Dupla desfeita, o diretor segue numa silenciosa viagem em homenagem ao amigo, registrando suas descobertas, surpresas, com lentes apontadas para o devir, a amizade, e para a consonância das relações, sentido e transitoriedade da vida.

Um pensar sobre a condição humana, compondo com o cinema um híbrido sensorial e reflexivo. Distante das narrativas clássicas, especialmente a narrativa indireta objetiva e/ou próximo da indireta livre (TEIXEIRA, 2012), agrega características do documentário poético, expositivo, participativo, reflexivo e performático (NICHOLS, 2005), ampliando as potencialidades do gênero, a partir da criatividade de seu diretor, ao usar, simultaneamente, enquadramentos não convencionais e conceitos como metalinguagem, paisagem sonora etc.

Entre ruídos, diálogos, trilha musical inédita e exclusiva de Plinio Profeta, e belas imagens das planícies e de alguns centros urbanos da Bolívia e do Chile, além de tomadas subaquáticas de Fernando de Noronha, eis que o filme não se estrutura em entrevistas e depoimentos sequenciados, mas resulta de um processo dinâmico e uníssono que envolve uma sublime e "permanente negociação" (LINS; MESQUITA, 2008, p.26), ao passo em que reserva surpresas ao espectador, que, a esta altura, já se convence de que também viaja com Mário e Eric.

O artigo busca ampliar o debate sobre fronteira, esgarçamento, conexão e amplitude de uma linguagem cinematográfica comprometida com a arte contemporânea, a autobiografia, o devir, o afeto e a experiência/engajamento sensorial do outro. 


\section{Performance autobiográfica em road movie}

Como o próprio movimento do cinema, cada vez mais reflexivo desde os anos 1960, os filmes documentais apontaram, mais sistematicamente, a câmera e a narrativa para si, e disso resultaram experiências singulares. Expressões como subjetividade e autorrepresentação continuam chaves para entender o cinema no mundo contemporâneo. Lins e Mesquita (2008) mapearam, a partir da análise de um corpo de filmes, as principais tendências dos documentários contemporâneos, dentre as quais destacamos, por conta de aderência ao documentário em questão, os filmes subjetivos e os ensaios fílmicos ${ }^{4}$.

Nos filmes subjetivos, também chamados filmes em primeira pessoa, ou simplesmente autorrepresentações, as imagens que partem dessa postura enunciadora do "cinema do eu", do "relato de si" implicam obviamente um olhar autorreflexivo, permitindo inclusive um autoquestionamento do dispositivo: "voltado para si mesmo, o sujeito não tem outra opção de exterioridade senão pondose em cena, logo tornando presentes suas próprias condições de existência enquanto imagem" (DUBOIS, 2012, p.4). Por outro lado, posicionam "a problemática na ordem explícita da subjetividade, na ordem da vida psíquica e dos processos de memória" (DUBOIS, idem, p.5).

Já os ensaios fílmicos englobam modos distintos de abordagem, composição, objetos e discursos heterogêneos. A filmagem torna-se o lugar onde as personagens são convocadas a se produzir, devir e fluir livres se estruturam como a dinâmica do filme, sendo a "[...] imagem um dado a ser trabalhado e relacionado com outras imagens e sons, e não mera ilustração de um real preexistente" (LINS; MESQUITA, 2008, p. 55).

Uma passagem para Mário pode ser alinhado a essas duas tendências, tanto porque o dispositivo de construção do filme o transforma, quanto porque se transforma o diretor, que assume, frente às telas, consistência de personagem na narrativa, realizando o sonho de seu amigo recém-falecido.

O filme agrega e registra processo, personagem e performance. É um híbrido, uma vez que estabelece conexões com muitos elementos característicos do cinema ficcional. O drama, enquanto conflito, é apenas um deles. É um road movie, em muitos sentidos, e também se aproxima do que se entende por imaginação melodramática (BROOKS, 1995).

Trata-se de um road movie porque, para além do registro da viagem, do fato de o filme fazer-se em processo, como reforça Laurence, transborda no filme a ideia das passagens: passagem como bilhetes de viagem, passagem da vida à morte, passagem de estar em outro lugar, de se colocar em movimento, de deslocar-se. Movimento no sentido de construção do próprio dispositivo que propicia o filme acontecer, de exposição de afetos, de busca quase espiritual para fechar um ciclo. Passagem, enfim, de trânsito entre as imagens, os "lugares" (variação de conteúdo audiovisual produzido pelo diretor e pela própria personagem), entre o acordo cinematográfico e o inesperado, entre a vida e a passagem.

Tudo isso nos mostra que nos campos do cinema, e especificamente do documentário contemporâneo, as imagens e narrativas encontram-se no espaço do entre-imagens, das passagens que determinam seus ritmos e discursos, sua identidade. No caso de Uma passagem para Mário, o filme se faz no movimento mesmo de passagem, referenciando o próprio cinema, tornando-se metalinguagem. No trânsito das imagens, na apresentação de fragmentos do roteiro, a passagem da própria vida que segue, em fluxo; do fluxo das cenas de intimidade familiar à poesia dos mergulhos, das cenas de viagem à projeção das imagens iniciais, e também últimas, que se reencontram no destino esperado.

\footnotetext{
${ }^{4}$ As experiências dos documentários em primeira pessoa têm sido amplamente discutidas na contemporaneidade, incluindo a análise dos documentários de busca (BERNARDET, 2005), dos filmes-dispositivo (MIGLIORIN, 2005).
}

R. Inter. Interdisc. Art\&Sensorium, Curitiba, v.8, n.1, p. $001-008$ Jan.- Jun. 2021 
Reconhece o diretor que o filme tem uma "abordagem processual", que se faz no percurso, se vai construindo, se transborda de destino. O processo gera, assim, uma exposição gradativa do diretor que no desenrolar do filme vai ganhando consistência de personagem. Para o filme acontecer, foi necessário operar um deslocamento, aceitar expor-se, como o amigo Mário, que sempre se mostrou sem resistência: "precisei me despir do receio de me expor para que o filme fosse realizado, isso acabou sendo uma condição imprescindível para o novo dispositivo do filme.” (LAURENCE, 2013).

Indubitavelmente, uma produção emblemática no campo da narrativa documental contemporânea em que tanto a personagem, quanto a performance, ocupam os lugares centrais da trama discursiva, dos conflitos e dos desdobramentos destes. No caso do filme em questão, tudo isso acompanhado de uma provocação estética a partir do encontro e hibridismo de linguagens, tais como cinema, artes plásticas, música etc.

Há que se considerar, também, que este documentário, a partir de sua sequência de acontecimentos e escolhas estéticas, acaba por produzir ou conduzir o espectador a uma espécie de "engajamento sensório-sentimental que atua como dinâmica de mobilização entre público e narrativa" (BALTAR, 2007, p.4). Esse parece ser exatamente o tipo de arrebatamento de Uma passagem para Mário, cinema dirigido à sensibilidade, que possibilita um "engajamento afetivo" e se articula à memória, como lugar e como ato. Os momentos de tessitura da memória dão credibilidade ao que é da ordem do íntimo, do inacessível: o "engajamento afetivo que se estabelece através da narração da memória é o que reveste de autenticidade tais momentos da narrativa (os momentos de performance, do ato da memória em si)" (BALTAR, 2007, p.137).

Considerando, entre outros aspectos, que intimidade e autenticidade são elementos essenciais do discurso fílmico, as performances seriam, então, essa memória como ato, que iniciam e consolidam laços afetivos, mas também fomentam reflexões ancoradas na transitoriedade da existência. No filme, isto e muito mais, apresentado ao espectador, que, por sua vez, passa a participar do jogo sensível do

filme, "embarcando" na viagem com o Diretor e nos diversos momentos do protagonista, que parece ter feito a passagem de modo sublime, poético e performático, potencializando os processos integrantes do road movie.

\section{A sensorialidade e o devir}

O filme apresenta um conjunto significativo de provocações sensoriais ao espectador, fato que potencializa a sua inserção e adesão à narrativa, mas, também que fomenta e instala uma relação com a arte contemporânea, especialmente aquela que desestabiliza, esgarça fronteiras estéticas, fragiliza hegemonias etc.

Na obra em questão, as provocações se dão, além do que já foi aqui mencionado, por uma trilha sonora que explora e contempla diversas fontes, e por imagens abstratas produzidas a partir de elementos do cotidiano do mergulhador e do diretor, em sua missão de realização processual, quase instalação.

Acerca da trilha sonora, uma leitura possível é a de que o documentário é permeado pelo conceito de paisagem sonora (SCHAFER, 1991), fomentando a ampliação do universo de escuta do espectador para um meio ambiente sonoro que valoriza fontes que poderiam ser compreendidas como ruídos, como é o caso daqueles advindos do para-brisa, da chuva, do avião, da aeromoça, do naufrágio, do trânsito e do ônibus na Bolívia... Os ruídos da respiração no mergulho das cenas iniciais, ou o áudio dos registros feitos pelo Mário Duques sempre acompanhado de legenda.

Após onze minutos de registros visuais e enquadramentos nada convencionais acerca do cotidiano de Mário, alternadas com imagens e áudios do fundo do mar, respiração subaquática, diálogo com o 
oncologista Iran Costa, áudio sem imagens e alternância com imagens do naufrágio, é que surge o título. A esta altura, o espectador já se encontra suficientemente na trama. E a escuta é participativa, ou seja, mergulhamos junto com ele e o diretor. Em outras palavras: à narrativa já estamos conectados, engajados.

Acerca da trilha musical, Eric Laurence opta por quatro obras originais produzidas por Plínio Profeta ${ }^{5}$, que prioriza poucos instrumentos nas canções, melodias e rítmica, invariavelmente nostálgicas. As obras musicais reforçam a proposta de engajamento afetivo e interatividade obra/público.

Ao final, já com o diretor em quadro ou fora dele, há o uso do silêncio como recurso sensorial. Um silêncio que estronda, por Mário já ter feito sua passagem, e, também, pelas paisagens do deserto do Atacama, da solidão/sofrimento do diretor em sua trajetória de cumprir a missão de levar Mário àquele local.

Por outra abordagem, o filme também nos apresenta o silêncio a partir da contemporaneidade de John Cage, em que se sublinham aspectos como tranquilidade e valores orientais; oposição ao som; resistência à poluição sonora dos centros urbanos e sociedade pós-industrial; silêncio como música, tensionando a escuta para a paisagem sonora do ambiente, ou seja, amplificação tecnológica da escuta do espaço apresentado e etc.

Acerca do devir, Mário nos transfere e/ou socializa a realidade da morte numa perspectiva de transbordamento do possível, do cartesiano, realçando a necessidade de reflexão e exercício de valores mais substantivos. Mário e sua incapacidade de lutar contra o câncer, seu percurso de dor sem vitimização, mas, não obstante, também nos transfere a iminência de fazer a sua passagem.

O devir também constituído na curiosidade de Mário acerca do campo da cinematografia, e numa produção audiovisual desacompanhada, em muitos momentos, de roteiro, e de conceitos como amador/profissional, certo ou errado.

O filme, assim, está muito próximo da racionalidade substantiva defendida pelo sociólogo Guerreiro Ramos (1981), em contraposição à racionalidade utilitária centralizada pelo mercado/capital, quando afirma que os indivíduos poderiam priorizar princípios como da autorrealização, da busca de emancipação e da satisfação social, reconfigurando a experiência e condição humana. A amizade entre Mário e Eric não se enquadraria como exemplo desta racionalidade substantiva? Isto pode ser percebido, em uma das respostas de Eric Laurence (2015):

O objetivo era que a câmera captasse "tudo" que estava sendo vivenciado, que fosse não apenas o meu olho, mas também o meu coração, que a câmera pudesse captar "subjetividade" nas imagens, na abordagem processual. Esses termos podem ser muito complexos, mas a idéia era simplesmente captar imagens que pudessem traduzir subjetivamente o que estava sentindo e conduzir isso para a diegese do espectador - transformar o filme em uma experiência visual e sensorial através do olho da câmera, do meu olho, tornando-se então o olho do próprio espectador.

O substantivo, aqui apresentado, não somente pelos efeitos de valorização da emoção, da amizade, do sensorial, mas, não raro, pelo propósito de consecução dos sonhos, dos encontros, dos riscos possíveis e necessários, e da liberdade da condição humana. Neste sentido, o regime escópico da racionalidade utilitária/instrumental perde força, ganha fissuras, e as lentes apontam para o intangível e o substantivo presentes nas relações humanas apresentadas no filme: a disposição para a realização dos sonhos e a inquietação criativa do artista quando se depara com obstáculos.

\footnotetext{
5 As obras musicais originais são: "Uma passagem”, "Para Mário”, “Astúria” e "Solo". 
Uma passagem para Mário substancializa a própria linguagem audiovisual a partir da escolha da afetividade e da sensorialidade como elementos centrais da narrativa, que, por sua vez, tem parte significativa de sua tensão centrada na realização e autonomia humana.

A racionalidade substantiva observada no filme desloca o espectador à medida em que o surpreende, em que lhe retira de um lugar óbvio e previsível, ora com imagens autorais do próprio Mário, ora com encontros inusitados que celebram a amizade, ora com o desafio do Diretor em finalizar o desafio inicial de forma sublime, poética e visualmente impactante.

Ainda acerca do substantivo nas escolhas de Eric Laurence, destaque para as cenas finais que reapresentam Mário Duque mergulhando, mas, desta vez, estas são projetadas nas formações rochosas do deserto do Atacama, considerado como território dos mais altos e áridos do planeta. Trecho emblemático do documentário, símbolo da concretização do sonho do amigo e companheiro de jornada, passagem etc.

Esta possibilidade de apreciação e leitura da obra audiovisual em questão, realça o mergulho na experiência humana, esgarçando os limites e possibilidades das realizações audiovisuais contemporâneas, especialmente uma linguagem documental híbrida, road movie e performática. Para Teixeira, em afinada sintonia com a liberdade artística de criação, expressão, provocação e política, porque não dizer: "A história, a história do cinema, pode ser bastante labiríntica quando posta sob o signo da ruptura, do acontecimento disruptor" (2012, p.160).

Não obstante, registra, ainda, Uma passagem para Mário possui uma forte tendência a realçar a atualidade e relevância do discurso deleuziano, acerca do campo das possibilidades relacionais entre o humano e suas tecnologias: “[...] as máquinas são sociais antes de serem técnicas. Ou melhor, há uma tecnologia humana antes de haver uma tecnologia material" (DELEUZE, 1988, p.49). Em outras palavras, aquele que opera máquinas e dispositivos, seja no cinema ou qualquer linguagem estética, o faz com sua cultura, valores e crenças.

\section{Considerações finais: a obra e seus desdobramentos}

A obra traçou linhas de fuga para além da tela. Embora nela, já tenha alcançado a proeza de, à época de seu lançamento, mesmo sendo um documentário nacional independente (o que em geral não interessa muito aos espaços comerciais exibidores no Brasil), conseguir ocupar 14 salas de cinema. O fato é que não estar vinculado a grandes redes de distribuição é a regra da produção documental nacional independente, e, tal fato permanece como um relevante desafio para as agências governamentais.

Assim como a vida de Mário não termina com sua morte biológica, o filme segue além de sua produção e projeção convencional, se desdobrando no projeto "1.000 Cineclubes", que ocupou espaços alternativos de exibição como estratégia de difusão e democratização do filme. "No final, eu liberei completamente o filme para download. Ele ficou disponível no site do Fantástico e na plataforma Vimeo. Também teve exibição no Canal Brasil, o que foi ótimo para ampliar mais ainda o número de espectadores", informa Eric Laurence, em entrevista, via internet.

Além destes, o filme se constituiu enquanto mote para um concurso, organizado pelo próprio Diretor, que convoca as pessoas a declararem amor aos seus amigos, publicamente: "Leve seu amigo para o deserto do Atacama".

Assim, de alguma forma, através das iniciativas acima, a obra ficou acessível nas plataformas, oportunizando sua apreciação, mas, também, fomentou novas performances (auto)biográficas e

R. Inter. Interdisc. Art\&Sensorium, Curitiba, v.8, n.1, p. 001 - 008 Jan.- Jun. 2021 
sensorialidades, esgarçando, significativamente, a arte em sua dimensão política, quando esgarça e interfere, positivamente, na condição humana.

Nestes tempos, com visível predominância da dimensão econômica sobre boa parte das populações, realçar a arte do encontro e despedida com poesia, o afeto, o tempo entre amigos, a sensibilidade, o silêncio, o direito e respeito aos sonhos, inscrevendo a morte como uma "passagem", se apresenta como um posicionamento indispensável à experiência humana agregadora e, como aqui registrado, mais substantiva e menos utilitária.

A performance autobiográfica, aqui brevemente apresentada, é a do próprio filme, num processo constante de revelação e transparência, no propósito de viver e registrar o outro, seu sonho, mas, também, sua trajetória, passagem e experiência naquilo que se convencionou chamar de humanidade.

\section{Referências}

BALTAR, Mariana. Realidade lacrimosa: diálogos entre o universo do documentário e a imaginação melodramática. 2007. UFF, Tese de Doutorado, Universidade Federal Fluminenese, Programa de Pós-Graduação em Comunicação.

BERNARDET, Jean-Claude. Documentários de busca: 33 e Passaporte Húngaro. In: LABAKI, Amir; MOURÃO, Dora. (Orgs.). O cinema do real. São Paulo: Cosac Naify, 2005.

BROOKS, Peter. The Melodramatic Imagination Balzac, Henry James, melodrama and the Mode of Excess. Yale: Yale University Press, 1995.

CAGE, John. Silence. Midletown: Wesleyan University Press, 1961.

DELEUZE, Gilles e GUATTARI, Félix. Mil platôs - capitalismo e esquizofrenia. Volume 1. São Paulo: Editora 34, 2011.

DELEUZE, Gilles. Foucault. São Paulo: Brasiliense, 1988.

DUBOIS, Philippe. A imagem-memória ou a mise-en-film da fotografia no cinema autobiográfico moderno. In: Revista Laika, Laboratório de Investigação e Crítica Audiovisual da USP, São Paulo, junho de 2012.

LAURENCE, Eric. Entrevista com o diretor. Uma passagem para Mário. Recife. In: http://www.umapassagemparamario.com.br/\#diretor/. Acesso em: 22 set 2019.

LINS, Consuelo; MESQUITA, Cláudia. Filmar o real: sobre o documentário brasileiro contemporâneo. Rio de Janeiro: Jorge Zahar, 2008.

LINS, Consuelo. Dear Doc: o documentário entre a carta e o ensaio fílmico. In: Devires, Revista de Cinema e Humanidades. Belo Horizonte, UFMG, 2006.

MIGLIORIN, Cesar. O dispositivo como estratégia narrativa. Revista acadêmica de cinema. Disponível em: http://www.estacio.br/graduacao/cinema/digitagrama/numero3/cmigliorin.asp Acesso em: março 2019. 
NICHOLS, Bill. Introdução ao documentário. Campinas, SP: Papirus, 2005.

GUERREIRO RAMOS, Alberto (1981). A nova ciência das organizações: uma reconceituação da riqueza das nações. Rio de Janeiro: FGV, 1981.

SCHAFER, Murray. O ouvido pensante. São Paulo: Unesp, 1991.

TEIXEIRA, Francisco Elinaldo. Cinemas "não narrativos": experimental e documentário passagens. São Paulo: Alameda, 2012.

UMA PASSAGEM para Mário. Produção e Direção: Eric Laurence. Roteiro: Eric Laurence; Mário Duques. Pernambuco, 2014. Disponível em: https://youtu.be/O3AfrmzsxE4. Acesso em 22 set. 2017. 